\title{
An Adaptable E-Learning Architecture Based on Learners' Profiling
}

\author{
Maria Dominic \\ Department of Computer Science, Sacred Heart College, India \\ Email: dominic@shctpt.edu \\ Sagayaraj Francis \\ Department of Computer Science and Engineering, Pondicherry Engineering College, India \\ Email: fsfrancis@pec.edu
}

\begin{abstract}
These days modifications and supplements to e-learning are not enough to make them successful since flexibility and adaptability is missing. Different eLearning architecture provide different kinds of learning experience to the learners. The lack of adaptive system is due to "One size fits for all" concept. Currently the research is towards to learner oriented platforms putting student motivation, habits, expectations and learning styles (additional Koper, R.; Burgos, D (2005)). The concept of adaptation has become a prominent issue in elearning. Systems allow the users to change some system parameters and adapt their behavior accordingly is known as adaption process. Systems that adapt based on the systems assumption are called as adaptive systems (additional santally mohammed issack). Since the system adapts to a person and personalizes the learning process it can be also known as personalized system (additional Paramythis, A.; Loidl-Reisinger). So to serve the learning community better there was a necessity to profile them and identify their requirements and provide an adaptive elearning architecture which suits the individuals needs better. So the main objective of this research was to provide an adaptive e-learning system architecture which satisfies Felder Silverman learning style. FelderSilverman's learning model [FSLM] was chosen since FSLM synthesis of these theories can be designed to easily translate them into strategies into a university setup.
\end{abstract}

Index Terms - Learning, e-Learning, Virtual Learning, eLearning Standards, Adaptive e-learning systems.

\section{LEARNING}

An individual's way of processing information is said to be cognitive styles (CS) [1]. Humans have the cognitive ability to acquire and recognize information, map them to representations and then to knowledge and then use them. Some of the CS are Cognitive Trait Model and Inductive Reasoning Ability [2]. Learning is a two phase process that involves reception and processing of the information received. Reception involves the various senses to gather information from external sources whereas the processing involves internal activity like memorization, induction, deduction, introspection, reflection etc. Every learner has his preferred way of reception and process the information and such activity is known as a learning style. Learning Styles are the different ways in which learners perceive and process information [3]. Several learning styles have been in [4] towards designing e-learning materials based on multilearner style [5]. Mostly the authors classify the learners into groups and propose corresponding inventories and methods. One of the two theories used in this research is Sarasin model [6]. According to him, the learners are classified into three groups based on their learning styles namely visual learners, auditory learners and kinesthetic learners. Visual learners gain knowledge through visual inputs, auditory learners learn through listening and kinesthetic learners learn through experiments and exploration. According to Felder-Silverman [7] there are 32 different styles of learning.

Table 1. Sarasin Model Learning Style

\begin{tabular}{|l|l|l|}
\hline \multicolumn{2}{|l|}{ Learning Style } & Description \\
\hline \multirow{3}{*}{ Visual } & Linguistic & Learn from reading and writing \\
\cline { 2 - 3 } & Spatial & $\begin{array}{l}\text { Learners visualize their learning } \\
\text { materials }\end{array}$ \\
\hline Auditory & $\begin{array}{l}\text { Learn by talking to themselves or } \\
\text { colleagues }\end{array}$ \\
\hline Kinesthetic & $\begin{array}{l}\text { Learn by doing, experiencing and } \\
\text { reflecting }\end{array}$ \\
\hline
\end{tabular}

Once a teacher becomes aware of these learning styles he will become more sensitive in designing classroom activities that enhances the teaching-learning process. Synthesis of learning style theories are tabulated in Table 4. The characteristics of these two models are given in Table 1, Table 2.

\section{E-LEARNING}

The utmost challenge to education is in helping the learners to learn to manage, work creatively and to contribute to knowledge creation [8]. With the advent of microcomputer the quest for e-learning or electronic learning revolutionized the field of education. 
Information and Communication Technology made great inroads into the field of education.

Since 1980 schools, colleges and universities started using computers in class room. Today ICT uses computer, peripherals and internet services in teaching learning process [9]. e-learning involves the use of computer in the teaching learning process. The media formats used in e-learning shown in following Table 3. Most of the resources can be replicated across the various platforms.

Table 2. Felder-Silverman Learning Style

\begin{tabular}{|l|l|}
\hline Learning Styles & Description \\
\hline Sensory & Concrete, Pragmatic \\
\hline Intuitive & Conceptual, Innovative \\
\hline Visual & Preferences to Pictures \\
\hline Verbal & Preferences to text/audio \\
\hline Inductive & Prefer explanation from concrete to general \\
\hline Deductive & Prefer explanation from general to concrete \\
\hline Active & Learn by experimentation and collaboration \\
\hline Reflective & Learn by thinking \\
\hline Sequential & Learn by small steps \\
\hline Global & $\begin{array}{l}\text { Learn by jumping from one topic to another in a } \\
\text { non linear manner }\end{array}$ \\
\hline
\end{tabular}

E-learning systems can be called using various names but they are basically same. They are virtual learning (VLE), e-learning management systems (e-LMS), learning content management system (LCMS), managed learning environment (MLE), etc...

Table 3. Media Formats of e-Learning

\begin{tabular}{|l|l|l|l|}
\hline \multirow{4}{*}{ e-learning } & Stand Alone & \multicolumn{2}{|l|}{ Magnetic Tapes, Disks, Laser Disks } \\
\cline { 3 - 4 } & \multirow{3}{*}{ Online } & \multirow{2}{*}{ Lan } & File Sharing \\
\cline { 3 - 4 } & & Intranet \\
\cline { 3 - 4 } & & \multirow{2}{*}{ Wan } & BBS \\
\cline { 3 - 4 } & & Internet \\
\hline
\end{tabular}

In Europe the term followed is VLE whereas it is CMS in USA. VLE is a computer software which uses text, graphics, illustrations, sound, video, graphics, multimedia etc... for the purpose of gaining knowledge on the area of study. There are several VLEs offered, some commercial and others open sources. The most popular ones are MOODLE, BLACKBOARD and WebCT [10]. VLE technology framework is as given in Fig 1.

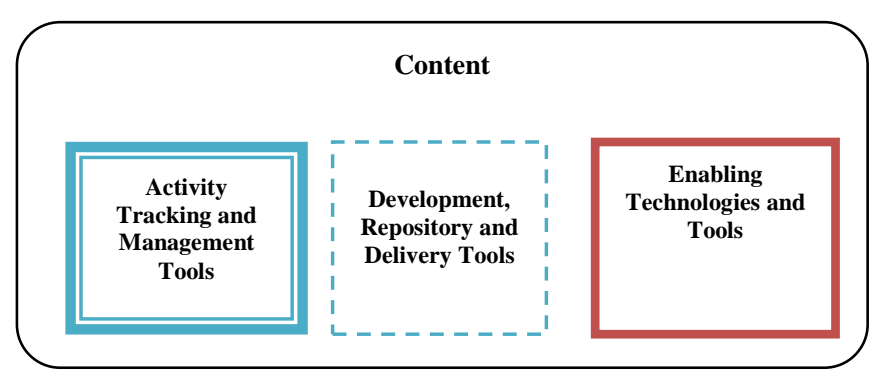

Fig 1. VLE Technology Framework
The main difference [11] between learning in a VLE and in traditional learning is that in learning is a comprehensive and length process instead of short term classes and the role of the teacher changes to an organizer rather than information deliverer. In order to enhance individualized learning experience information about students' backgrounds and preferences should be stored thus providing adaptable VLEs. The simplest way to do that is to gather information from the learners as it is done in this thesis. Another way is to capture the learners behavior automatically from the VLE as it was done in Online e-Learning System developed from web 2.0 tools. Graf pointed out in 2007 how well open source VLE can adapt to learning styles and which can be extended to adaptive VLE. The minimum qualities a VLE should expose are it should be usable to many people, stable, less error prone and easy to install and customize. The learning contents come in many forms. To curate the different types of content there are many software available in the market. The type of contents can be documents, presentations, HTML files, web media, interactive media, audio, video, animations etc. As the number of courses and the amount of the content increases there is a necessity to implement a management process. So the management process should take care of the storage, security and distribution. For the content and management process to function it requires other underlying infrastructure and tools to function. They can be Intranet and Internet, Application Development Tools like Java, JSP etc..., Databases (Relational or as per required), Special Protocols (like video H.323), Other considerations like network bandwidth, server platforms.

E-learning evolved along with the evolution of web. The characteristics of the different generations of web are listed in Table 5 and the characteristics of different generations of e-learning are provided in Table 6.

Table 5. Characteristics of Web 1.0, Web 2.0 and Web 3.0

\begin{tabular}{|l|l|l|}
\hline Web 1.0 & Web 2.0 & Web 3.0 \\
\hline Read & Read and Write & Read, Write and Execute \\
\hline Client Server & Peer to Peer & Portable Personal Web \\
\hline HTML, Portals & XML, RSS & RDF \\
\hline Companies Own & Communities Share & Individuals \\
\hline Web Pages & Web Applications & Semantic Applications \\
\hline
\end{tabular}

Table 6. Relationship between generations of e-learning

\begin{tabular}{|l|l|l|}
\hline Version & Concept & Technologies \\
\hline \multirow{3}{*}{1} & $\begin{array}{l}\text { Content Management } \\
\text { Read or Write Only }\end{array}$ & $\begin{array}{l}\text { CBT, Learning Management } \\
\text { Systems, eBooks, Virtual } \\
\text { Learning Environment }\end{array}$ \\
\hline \multirow{3}{*}{3} & $\begin{array}{l}\text { Read and Write } \\
\text { Blended Learning, } \\
\text { Content Authoring, } \\
\text { Collaborate, } \\
\text { Multimedia Content }\end{array}$ & $\begin{array}{l}\text { LCMS, Social Networks, } \\
\text { Audio/ Video Conference } \\
\text { Social, Mashups }\end{array}$ \\
& $\begin{array}{l}\text { Learner-Centric, U- } \\
\text { learning, Knowledge } \\
\text { representation }\end{array}$ & $\begin{array}{l}\text { PLEs, Mashups Social, } \\
\text { Semantic Web, Personal } \\
\text { Agents, Big Data, Linked Data, } \\
\text { 3D, Global Database }\end{array}$ \\
\hline
\end{tabular}


Table 4. Learning Styles

\begin{tabular}{|l|l|l|l|l|l|}
\hline Author & \multicolumn{4}{|c|}{ Characteristics } \\
\hline $\mathbf{1}$ & Accommodating & Diverging & Converging & Assimilating \\
\hline $\mathbf{2}$ & Activists & Reflectors & Theorists & Pragmatists \\
\hline $\mathbf{3}$ & Environmental & Emotional & Sociological & Psychological \\
\hline $\mathbf{4}$ & $\begin{array}{l}\text { Active / } \\
\text { Reflective }\end{array}$ & Visual / Verbal & Sensing / Intuitive & Sequential / Global \\
\hline $\mathbf{5}$ & $\begin{array}{l}\text { Visual } \\
\text { Author [1 - David Kolbs' 2-Peter Honey and Alan Mumfords' 3 - Dunn and Dunn 4 - Felder-Silverman 5 - Sarasin] }\end{array}$
\end{tabular}

\section{A. Challenges in e-learning}

The first major challenge is due to the nature of web, its vastness, interoperability, lack of server side checks, less privileges control and increased privacy and security risk [12]. The second major issue is whether the current education scenario is ready to utilize the benefits of latest technologies of the web when they are still struggling with the previous generations [13].

\section{E-LEARNING STANDARDS}

The primary technology related issue in e-learning is the sharing and interoperability of the learning resources among the various e-learning systems and various global information systems such as ERP, CRM, payroll and billing systems. Standards are conditions for interoperability making content from one system run on any other compatible system [14] therefore increase flexibility. Some of the various standards proposed namely are as follows,

AICC [15] - Aviation Industry CBT committee developed guidelines for aviation industry related training programmes and this has been used for interaction with CBT.

DUBLIN CORE METADATA INITIATIVE [16] - It is an organization dedicated in promoting interoperable meta data standards and developing meta data vocabularies.

IMS [17] - Instructional management systems global learning consortium which focuses on higher education.

ADL [18] - Advanced distributed learning imitative is a program for US defence department has developed guidelines for large scale development and implement of distributed learning.

ARIADNE [19] - Alliance of remote instructional authoring and distribution networks for Europe is an European union project which focuses on development of tools and methodologies for producing, managing and reusing learning objects.

IEEE - LTSC (LEARNING TECHNOLOGY STANDARDS COMMITTEE) is charted by IEEE Computer Society Standards Activity Board. It provides specifications by coordinating with other organizations. The popular five which are active still are P1484.1 Architecture and Reference Model WG, P1484.11
Computer Managed Instruction (CMI) WG, P1484.12 Learning Objects Metadata (LOM) WG, P1484.18 Platform and Media Profiles WG, P1484.20 Competency Definitions WG.

LEARNING OBJECT METADATA (LOM) - From 2002 onwards Learning Object Metadata (LOM) has been approved as IEEE-SA standard and became a international standard. LOM is based on ARIADNE, IMS and DCMI. It defines a structure for interoperable learning objects.

COMPUTER MANAGED INSTRUCTIONS (CMI) This group worked to strengthen mainly on the aspects already covered in AICC LMS communication interface AGR010/CMI001 comply with other ISO Standards. The latest revision focuses on JavaScript based communication instead of http based one as in ADL

ARCHITECTURE AND REFERENCE MODEL LEARNING TECHNOLOGY SYSTEMS ARCHITECTURE (LTSA) aims to provide a framework for understanding existing and future systems and promotes interoperability and to become adaptable to new technologies. [LTSA 2001] document differentiates five layers.

PLATFORM AND MEDIA PROFILES - This group identifies the other standards that can be useful for elearning.

MICROSOFT LRN - Learning Resource iNterchange is a reference implementation of IMS content packaging specification. The latest version 3.0 is available at [20].

CEN/ISSS WS-LT - Learning Technologies Workshop for standardization created CEN/ISSS to ensure standards for European needs. More information available at [21]

PROMETEUS - PROmoting Multimedia Access to Education and Training in EUropean Society was launched in 1999 for promoting multimedia access to education throughout European society. More details about the association can be found at [22].

\section{Proposed AdAPtIVE E-LEARNING ARCHITECTURE}

The findings from the studies undertaken [23, 24] are,

- The learning objects ratio preferred by the sampling population would be $40 \%$ visual, $40 \%$ kinesthetic and remaining $20 \%$ audio learning objects.

* Each learning objects under the three categories are, 


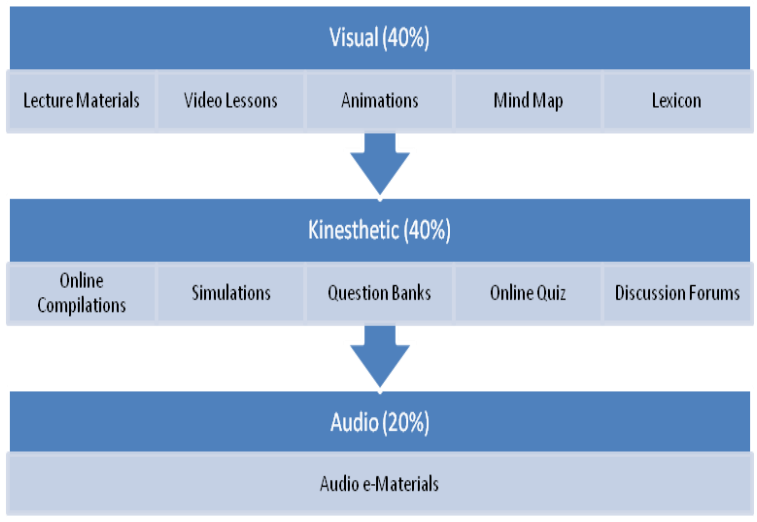

Fig 2. Preferred Learning Objects

The following Figure 3 depicts the individualized learning path based on three parameters considered for the survey, qualification, gender and domicile. To have more specialized learning path for the combination of the parameters Table 10 can be seen which provides the required statistics.

The proposed architecture satisfies all the objectives identified, ie attending, apprehending, investigating, exploring, discussing, debating, experimenting, practicing, articulating, expressing, in general conceptualization, construction and application in the e-learning system. The learning components in the e-learning system preferred by the sample population comprises of $40 \%$ visual and $40 \%$ kinesthetic and $20 \%$ audio components and the individualized learning path for the various classification of the learners is given in Figure 3. This study results in designing the following adaptable e-learning system architecture represented in Figure 4. The main models in this adaptive e-elearning system are Learner Model, Adaptation Model and Content Model.

\section{A. Learner Model}

This model interacts directly with the learners community. It performs the following tasks,

1. All the request and response will be through HTTP/HTTPS format.

2. All the request from the learning activity passes through a load balancer which balances the loads based on the proposed data structure and the algorithm identified in [25].

3. It collects data related to learners' profile, learning behavior and passes them on to the adaptation model which stores them in a repository to form a pattern and adaptation rules.

4. It responds back to the learners with the personalized learning contents provided by the adaptation model.

\section{B. Adaptation Model}

This is the main processor for the proposed adaptative e-learning system. It performs the following tasks,

1. It stores all the learners profiles and their learning patterns into a repository.

2. In the proposed system the findings of the studies are inbuilt into the system to simplify its task of responding to the learners.

3. In addition to it, this model also captures and updates the browsing behavior of the learners to its knowledge based already acquired so that it keeps on follows the transition of the learners.

4. Using the knowledge repository about the learners profile the adaptation rules module forms or identifies the learning style, learning path and the learning contents for the identified learner and builds the personalized learning contents and passes them on to the learners' model to present to the learner.

5. The model retrieves all the contents required from the content model.

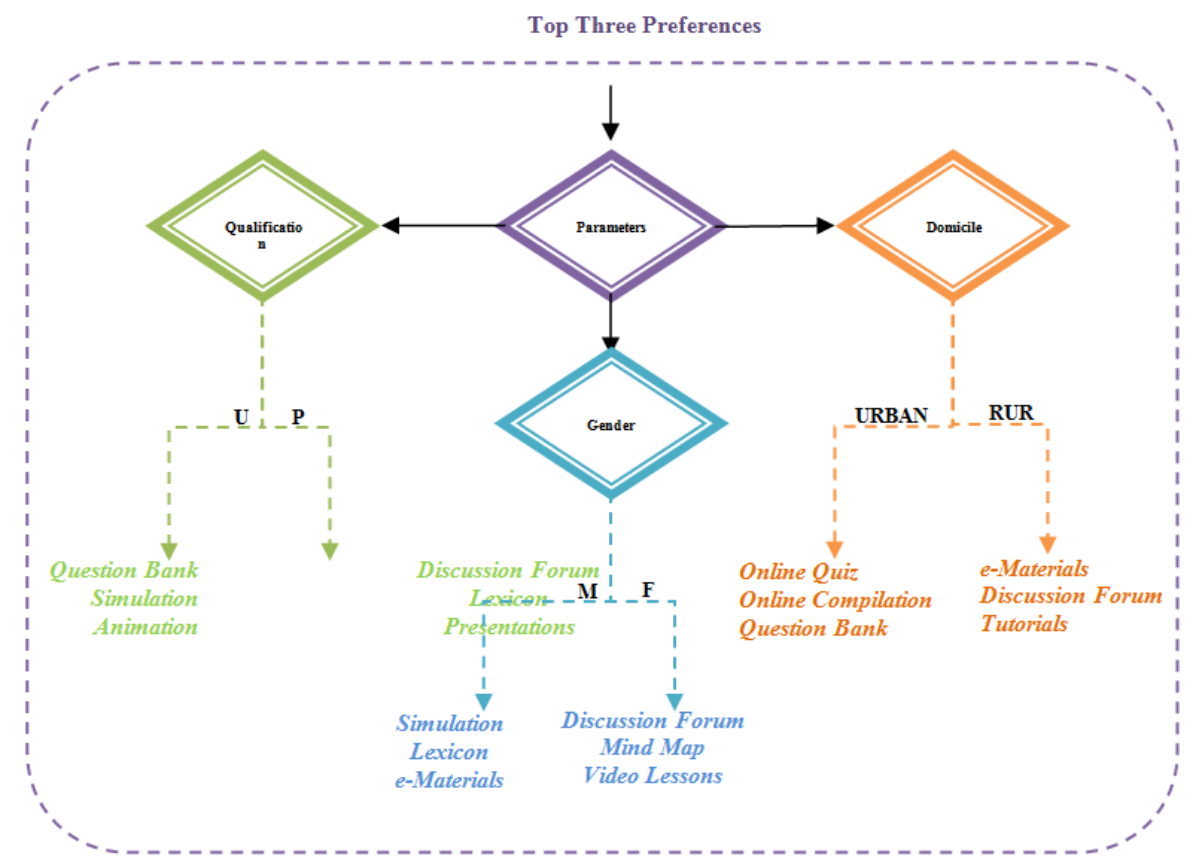

Fig 3 - Individualized Learning Path based on qualification, Gender and Domicile 


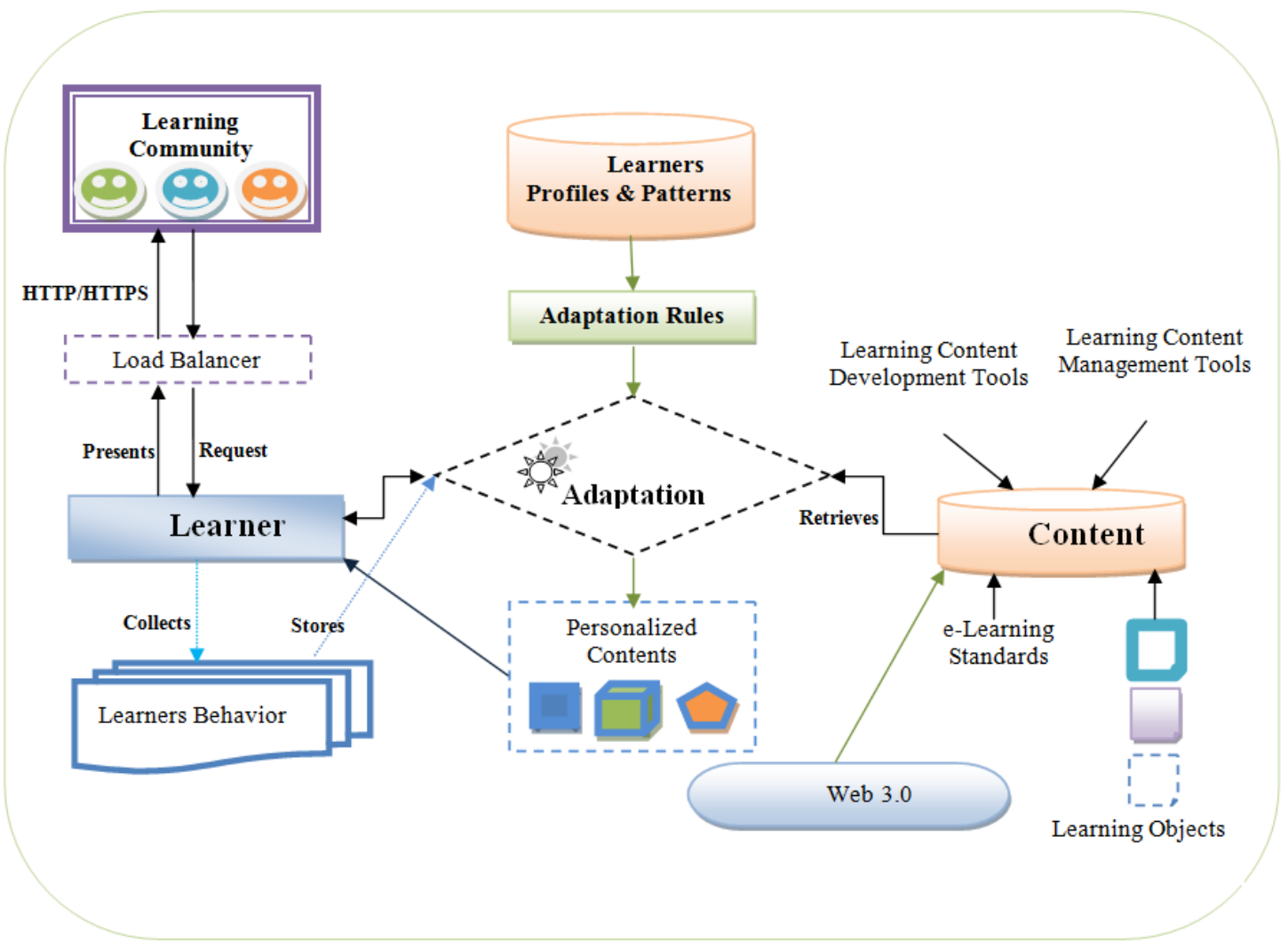

Fig 4. Three Layer Architecture for adaptive e-learning system

\section{Content model}

This model performs the following tasks,

1. It acts as a repository for all the learning objects developed by the tutor.

2. The tutor should develop the contents based on the ration identified from the study made on the sample population, i.e. $40 \%$ visual contents, another $40 \%$ kinesthetic contents and remaining $20 \%$ audio contents. In order to curate the contents the latest web technologies can be utilized, in this case the current generation of web is 3.0 so its technologies can be used for content creation.

3. This model also contains learning content development and management tools, as well as the learning standards to make this system compatible, shareable and interoperable with other e-learning systems.

\section{CONCLUSION AND FUTURE WORK}

This research focused on enhancing the learning experience based on learners profile and their preferences. To provide a better e-learning system depends upon the cognitive aspects such as motivation level, likes, dislikes, age group, domicile and gender for better classification. Extraction of the useful patterns and relationships from the data set in the need of the hour and is becoming a vital part of data mining. Based on the data analysis the on the users preferences the proposed architecture provides a adaptive personalized sequential learning path according the different classified learners to suit their learning styles. With the extraction of the subjective information about the user preferences the outcome becomes very subjective. In this research a various learning paths based on the users classification which were identified. In order to generalize the system and make it outreach more for a general population the learning theorist should develop new classification techniques.

The research could be extended to identify the stress levels of the individuals and handle them in the e-learning system. User interface design principles could be utilized to improve the learners learning and cognitive skills. Data collection could be increased to wider geographical range to make this system internationally useful. Semantics could be use more to induce artificial intelligence into the system.

\section{REFERENCES}

[1] Anita Finke, Janis Bicans, 2010. E-Learning System Content and Architecture Evolution, Proceedings of 16 International Conference on Information and Software Technologies.

[2] Stash, Cristea, De Bra, 2006. Adaptation to Learning Styles in E-Learning: Approach Evaluation, Proceedings of E-Learn 2006 Conference.

[3] Lavanya Rajendran, Ramachandran Veilumuthu, 2011. A Cost Effective Cloud Service for E-Learning Video on Demand, European Journal of Scientific Research, pp. 569-579. 
[4] Zhang Guoli, Liu Wanjun, 2010. The Applied Research of Cloud Computing Platform Architecture in the ELearning Area, IEEE.

[5] Thaddeus, Maria Dominic, 2008. Multi-Agent eLearning System for Programming Languages, Amazing Elearning.

[6] Sleigh, 2002. Learning Styles - from Theory to Practice. Training and Development in Australia, Australian Institute of Training and Development, 29(2), pp.44.

[7] Graf, Viola, Kinshuk, 2006. Representative Characteristics of Felder-Silverman Learning Styles: an Empirical Model, IADIS, pp. 235-242.

[8] N. Law, and E. Wong, 2003. Developmental trajectory in knowledge building: An investigation. In B. Wasson, S. Ludvigsen, and U. Hoppe (Eds.), Designing for Changes, Kluwer Academic Publishers, Dordrecht, pp.57-66.

[9] Paul G. Paris, E-Learning, 2004. A study on Secondary Students' Attitudes towards Online Web Assisted earning, International Education Journal, 5(1), pp 98 112.

[10] White Paper on elearning the future of learning, elearnity Ltd.

[11] O'Reilly, T., 2004. What is Web 2.0: Design patterns and business models for the next generation of software. http://www.oreillynet.com/pub/a/oreilly/tim/news/2005/ 09/30/what-is-web-20.html in March2012.

[12] Manninen, J. Kurssikoulutuksesta oppimisympäristöihin. In: Matikainen, J. \& Manninen, J. Aikuiskoulutus verkossa, 2000. Helsingin yliopiston Lahden tutkimusja koulutuskeskus, pp. 29 - 42.

[13] Meichel Blog. Meichel, F., Qu'est-ce que la cognition points de repères en sciences cognitives Qu'est-ce que la cognition - points de repères en sciences cognitive. Retrieved March 20, 2012 from http://florencemeichel.blogspot.com/2009/05/quest-ceque-la-cogntion-points-de.html. (English translation found at Wheeler, 2009b).

[14] Ron, Callari, 2009. Web 4.0, Trip Down the Rabbit Hole or Brave New World? http://www.zmogo.com/web/web-40trip-down-therabbit-hole-or-brave-new-world/
[15] Ravet, S., 2001. Raising the standard of e-Learning, Prometeus Newsletter 5. http://www.prometeus.org/news/PROMETEUS_Newsle tter5.pdf

[16] www.aicc.org

[17] http://dublincore.org.

[18] www.imsproject.org

[19] www.adlnet.org

[20] www.ariadne.unil.ch

[21] http://www.microsoft.com/elearn/support.asp

[22] http://www.cenorm.be/isss/workshop/lt/emlversion1.pdf

[23] http://www.prometeus.org

[24] Maria Dominic, Sagayaraj Francis, Philomenraj, 2013. Assessment of Popular E-Learning Systems via FelderSilverman Model and a Comprehensive E-Learning System, International Journal of Modern Education and Computer Science, 5 (11), pp 1-10.

[25] Maria Dominic, Sagayaraj Francis, 2014. E-Learning In Web 3.0, International Journal Of Modern Education And Computer Science, 6(2), pp 8-14.

[26] Maria Dominic, Sagayaraj Francis, 2014. Load Balancing using Peers in an e-Learning environment, International Journal of Computer Science and Business Informatics, 14(1), pp 22-29.

\section{Authors' Profiles}

Maria Dominic is currently an assistant professor in the Department of Computer Science at Sacred Heart College, Tirupattur, India. He is a research scholar in the field of eLearning and Cloud Computing.

Dr. Sagayaraj Francis is a professor in the Department of Computer Science and Engineering, Pondicherry Engineering College, Pondicherry, India. He specializes in Data Management, Data Modeling, Information Systems and eLearning.

How to cite this paper: Maria Dominic, Sagayaraj Francis,"An Adaptable E-Learning Architecture Based on Learners' Profiling", IJMECS, vol.7, no.3, pp.26-31, 2015.DOI: 10.5815/ijmecs.2015.03.04 